\title{
Watershed science: Bridging new advances in hydrological science with good management of river basins
}

Watershed science traditionally refers to the themes of hydrology and water resource management. Watershed science has been experiencing a rapid evolution that thrives on a forceful superimposition of multi-discipline and innovative earth observing and information techniques. The water and its interactions with other systems in a watershed is increasingly becoming a focus in scientific communities, and several new disciplines such as ecohydrology, ecoeconomics, environmental hydrogeology and hydroinformatics have emerged in recent years. From a water-soil-air-plant-human perspective, an integrated study should be implemented regarding a basin in its totality; this new science is called watershed science (Cheng et al., 2014).

This Special Topic on SCIENCE CHINA Earth Sciences provides a forum to discuss watershed science. Seven papers that are contributed from leading scientists working in the forefront of watershed science are presented. These scientists are from China, the USA, Japan, the United Kingdom and Germany. Although the number of the papers is relatively small, these papers cover the main fields and foundations of watershed science. To an extent, the special issue represents the epitome of watershed science.

Integrated modeling is always at the core of watershed science. This method synthesizes formal knowledge regarding our understanding of complex watershed processes. In this special issue, we are pleased to have Professor Keith Beven, one of the most influential hydrologists contribute his new results on hyper-resolution hydrological modeling (Beven et al., 2015). The earth system model, with resolution less than $1 \mathrm{~km}$, can be called the hyperresolution model. However, Beven and his colleagues argue that the hyperresolution model not only means the finer grids in the model, but also means finer and more reliable parameterizations to improve the accuracy and sensitivity of the model. Otherwise, the model will be lost in hyperresolution ignorance.

Two modeling works in the Heihe River Basin (HRB), well known as a representative arid region inland river basins in China (Cheng et al., 2014), are also published in this special issue. Yang et al. (2015) introduced their distributed scheme developed for ecohydrological modeling in the upstream areas of the HRB. Yao et al. (2015) established a numerical model of regional groundwater flow in the mid- and downstream areas of the HRB in which the oases and vegetation along the Heihe river corridor are highly dependent on groundwater.

The improvements of observational technologies and infrastructure for observing hydrological and ecological processes at the watershed scale reflect another aspect of the progress in watershed science. DeBeer et al. (2015) introduced the Changing Cold Regions Network (CCRN). The CCRN is a Canadian research consortium dedicated to understanding, diagnosing and predicting interactions amongst the cryospheric, ecological, hydrological, and climatic components of the changing earth system at multiple scales, mainly in western Canada. The Mackenzie and Saskatchewan River Basins in Canada are typical watersheds with rapid environment changes, and high vulnerabilities in the cryosphere and desert coexisting basins. CCRN provides opportunities to observe and understand processes and their interactions, to develop and test numerical simulation models, and to provide validation data for remote sensing products. Combined, these tools improve our understanding of and predictive capabilities for environmental management.

The integrated information infrastructure, has become increasingly important and plays a critical role in the Integrated River Basin Management (IRBM). The automatic acquisition, transmission, quality control and remote management of obser-

Citation: Li X, Zhang G L, He C S. 2015. Watershed science: Bridging new advances in hydrological science with good management of river basins. Science China: Earth Sciences, 58: 1-2, doi: 10.1007/s11430-014-5037-7 
vational data have been realized through employing wireless sensor network and other new technologies. Simultaneously, the observation and information systems have been highly integrated, which provides a solid foundation for establishing a research platform to foster watershed science.

Bogena et al. (2015) introduced the Eifel National Park integrated observatory in Germany, within the terrestrial network of observation (TERENO). The TERENO is to foster the understanding of water, energy, and matter fluxes and their biological and physical drivers within the river basins. To improve the understanding of the post-deforestation changes in ecosystem functioning under deforestation experiments, the key experimental network and observatory research in the Wüstebach catchment in the Lower Rhine Valley have been presented.

Koike et al. (2015) introduced a prototype GEOSS (Global Earth Observation System of Systems) that integrates the information infrastructure and ecohydrological modeling for water resource management in several river basins with different climate regimes in Asia. The system is based on integration of data from earth observation satellites and in-situ networks with other types of data, including numerical weather prediction model outputs, climate model outputs, geographical information, and socio-economic data. The structure of the system contains the cryospheric process, dam operation optimization scheme, and a set of tools for climate change impact assessment to generate relevant information for policy and decision makers.

The Decision Support System (DSS), which is established on scientific models, is critical to achieve the Integrated River Basin Management (IRBM). However, few examples of effective IRBM are found because of the quickly changing environment and the lack of integrated scientific support framework. Cai et al. (2015) provide an overview of the major challenges with IRBM, the promising scientific approaches for the implementation of the IRBM, and the areas of research required. They focus on important issues and experiences in China, notably in the HRB. Novel research is expected to draw together disparate disciplines into an integrated scientific framework, upon which better modeling tools, integrated observations, effective cyber-infrastructure support, stakeholder involvement, and decision-making support can be built. A new generation of the DSS and implementation of the IRBM are expected with the development of better modeling tools, stakeholder involvement, and decision-making support tools.

The papers included in this Special Topic are included in, but not limited to, the themes above. We hope this Special Topic published in SCIENCE CHINA Earth Sciences would stimulate further academic exchange and discussions and contribute to the better understanding of the emerging watershed science.

Beven K, Cloke H, Pappenberger F, et al. 2015. Hyperresolution information and hyperresolution ignorance in modelling the hydrology of the land surface. Sci China Earth Sci, 58: 25-35, doi: 10.1007/s11430-014-5003-4

Bogena H, Bol R, Borchard N, et al. 2015. A terrestrial observatory approach to the integrated investigation of the effects of deforestation on water, energy, and matter fluxes. Sci China Earth Sci, 58: 61-75, doi: 10.1007/s11430-014-4911-7

Cai X M, Marston L, Ge Y C. 2015. Decision support for integrated river basin management—Scientific research challenges. Sci China Earth Sci, 58: 16-24, doi: 10.1007/s11430-014-5005-2

Cheng G D, Li X, Zhao W Z, et al. 2014. Integrated study of the water-ecosystem-economy in the Heihe River Basin. Natl Sci Rev, 1: 413-428, doi: $10.1093 / \mathrm{nsr} / \mathrm{nwu} 017$

DeBeer C M, Wheater H S, Quinton W L, et al. 2015. The Changing Cold Regions Network: Observation, diagnosis, and prediction of environmental change in the Saskatchewan and Mackenzie River Basins, Canada. Sci China Earth Sci, 58: 46-60, doi: 10.1007/s11430-014-5001-6

Koike T, Koudelova P, Jaranilla-Sanchez P A, et al. 2015. River management system development in Asia based on Data Integration and Analysis System (DIAS) under GEOSS. Sci China Earth Sci, 58: 76-95, doi: 10.1007/s11430-014-5004-3

Yang D W, Gao B, Jiao Y, et al. 2015. A distributed scheme developed for eco-hydrological modeling in the upper Heihe River. Sci China Earth Sci, 58: 36-45, doi: 10.1007/s11430-014-5029-7

Yao Y Y, Zheng C M, Tian Y, et al. 2015. Numerical modeling of regional groundwater flow in the Heihe River Basin, China: Advances and new insights. Sci China Earth Sci, 58: 3-15, doi: 10.1007/s11430-014-5033-y

LI Xin

Cold and Arid Regions Environmental and Engineering Research Institute, Chinese Academy of Sciences E-mail: lixin@1zb.ac.cn

ZHANG GanLin

Institute of Soil Science, Chinese Academy of Sciences E-mail: glzhang@issas.ac.cn

HE ChanSheng 